\title{
Antocianinas, ácido ascórbico, polifenoles totales y actividad antioxidante, en la cáscara de camu-camu (Myrciaria dubia (H.B.K) McVaugh)
}

\author{
Antocianinas, ácido ascórbico, polifenóis totais e atividade antioxidante \\ na casca do camu-camu (Myrciaria dubia (H.B.K) McVaugh)
}

\section{Juan Edson VILLANUEVA-TIBURCIOํㅗ ${ }^{1}$ Luis Alberto CONDEZO-HOYOS ${ }^{2}$, Eduardo Ramirez ASQUIERI ${ }^{3 *}$}

\begin{abstract}
Resumen
Este trabajo fue realizado en la UNAS, Tingo María, Perú. Los objetivos fueron evaluar el contenido de antocianinas, ácido ascórbico, y polifenoles totales, en la cáscara fresca y seca de camu-camu (Myrciaria dubia (H.B.K) McVaugh) en diferentes estados de madurez; evaluar la actividad antioxidante en la cáscara seca, usando diferentes tipos de radicales (DPPH, $\mathrm{ABTS}^{+}$y Peroxilo) y correlacionar el valor de ácido ascórbico y polifenoles totales con la actividad antioxidante. La extracción fue realizada en medio acuoso, y los resultados de las evaluaciones de cada experimento fueron analizados por un diseño completamente al azar (DCA), según la prueba de t-student (p < 0,05). El extracto de la cáscara de la muestra madura fresca mostró las concentraciones más elevadas de ácido ascórbico y antocianinas en relación al pintón y verde, con 21,95 mg.g $\mathrm{g}^{-1}$ cáscara, y 46,42 mg..-1 de cianidin-3-glucósido, respectivamente, mientras que el extracto de la cáscara seca del pintón mostró el mayor valor de ácido ascórbico y polifenoles totales con 53,49 mg.g-1 muestra y 7,70 mg de Ac. Gálico/g muestra. La mayor actividad antioxidante, fue en los extractos de la cáscara seca de muestra pintón, con $\mathrm{IC}_{50}=46,20 ; 20,25$ y $8,30 \mu \mathrm{g} \cdot \mathrm{mL}^{-1}$ frente a los radicales $\mathrm{DPPH}, \mathrm{ABTS}^{+}$y Peroxilo respectivamente.

Palabras-clave: frutas del cerrado brasileño; camu-camu; vitamina C; antioxidantes; polifenoles.
\end{abstract}

\section{Resumo}

A pesquisa foi realizada na UNAS em Tingo Maria, Peru, teve como objetivos: avaliar o teor de antocianinas, ácido ascórbico e polifenóis totais, na casca fresca e na casca seca do camu-camu (Myrciaria dubia (HBK) McVaugh) em diferentes tempos de maturação; avaliar a atividade antioxidante na casca seca utilizando diferentes tipos de radicais (DPPH, ABTS ${ }^{+}$e Peroxilo) e correlacionar o teor de ácido ascórbico e polifenóis totais com a atividade antioxidante. A extração foi realizada em meio aquoso, os resultados das avaliações de cada experiência são analisados no delineamento inteiramente casualizado (DIC), pelo teste de t-student $(\mathrm{p}<0,05)$. O extrato da casca da amostra madura fresca apresentou as concentrações mais elevadas de ácido ascórbico e de antocianinas em relação a meio madura e verde, com 21,95 mg. ${ }^{-1}$ de casca e 46,42 mg. $\mathrm{L}^{-1}$ de cianidin-3-glucosídeo, respectivamente, enquanto que o extrato da casca seca meio madura apresentou o maior teor de ácido ascórbico em relação a madura e verde $\left(53,49 \mathrm{mg} \cdot \mathrm{g}^{-1}\right)$ e de polifenóis totais: 7,70 mg Ác. Gálico/g. A maior atividade antioxidante foi encontrada no extrato da casca seca da amostra meio madura com $\mathrm{IC}_{50}=46,20 ; 20,25$ e 8,30 $\mu \mathrm{g} \cdot \mathrm{mL}^{-1}$, em comparação com DPPH radical, $\mathrm{ABTS}^{+}$e Peroxílo respectivamente.

Palavras-chave: frutas do cerrado brasileiro; camu-camu; vitamina $C$; antioxidantes; polifenóis.

\section{Introducción}

El camu-camu (Myrciaria dubia (H.B.K) McVaugh), es una fruta nativa que se encuentra en la Amazonia Peruana y en el cerrado brasileño; esta se caracteriza principalmente por su alto contenido en ácido ascórbico, que supera significativamente a cítricos, como el limón y la naranja (50 a 60 veces más), debido a esta característica el camu-camu presenta un gran interés para ser explotado en la agroindustria y farmacia. También el reciente interés de polifenoles en plantas se ha enfocado por su gran potencial en beneficio de la salud humana, con particular referencia a los polifenoles de frutas y vegetales (DREOSTI, 2000; ZAPATA; DUFOUR, 1993).

Los antioxidantes naturales son preciados porque pueden ser usados en el diseño de alimentos benéficos para la salud (funcionales o nutraceúticos). La importancia de los antioxidantes es crucial para la salud, debido a su capacidad de neutralizar radicales libres, que contienen uno o más electrones desapareados (THOMAS, 2000), siendo responsables de muchas enfermedades degenerativas, cataratas, artereoesclerosis, muerte celular y cáncer, asimismo por su capacidad de eliminar y atrapar potencialmente a los electrófilos dañadores del ADN, metales tóxicos, hasta la inhibición de enzimas activadoras de precarcinógenos, hasta carcinógenos (FRIEDMAN, 1997). El antioxidante al colisionar con el Radical Libre (RL) le cede un electrón, oxidándose a su vez y transformándose en un RL débil no tóxico (PERÓN; LÓPEZ; J. R. M.; LÓPEZ, Y. T, 2001; ZHENG; WANG, 2001).

Recebido para publicação em 24/9/2008

Aceito para publicação em 18/7/2009 (003469)

${ }^{1}$ Grupo de Biotecnología Aplicada, Centro de investigación para el desarrollo biotecnológico de la Amazonia, Universidad Nacional Agraria de la Selva, Tingo María, Perú, E-mail: juanedvi@yahoo.es

${ }^{2}$ Grupo de Biotransformaciones de la U. Complutense de Madrid, España, Universidad Nacional Agraria de la Selva Tingo María, Perú, E-mail: lcondezo@hotmail.com

${ }^{3}$ Engenheiro de Alimentos, Faculdade de Farmácia, Universidade Federal de Goiás - UFG, CEP 74605-220, Goiânia - GO, Brasil, E-mail: asquieri@gmail.com

${ }^{*}$ A quem a correspondência deve ser enviada 
El mercado de estos productos es uno de los más emergentes, con niveles de venta de 12,9 billones de dólares en el año 2001, proyectándose un crecimiento para el año 2010 de 25,8 billones de dólares (SLOAN, 2002).

Zanatta et al. (2005) estudió las antocianinas de camu-camu por HPLC y H RMN, pues constató que tiene cianidina-3-glucosídeo como el principal pigmento en esta fruta seguido por la delfinidina-3-glucsídeo, y el total de antocianinas fue de $\left(54 \pm 25,9 \mathrm{mg} .100 \mathrm{~g}^{-1}\right)$. Ya Inoue et al. (2008), investigó el camu-camu referente a sus antioxidantes y antiinflamatorias en seres humanos y observó a 20 personas del sexo masculino fumantes voluntarios que tomaron $70 \mathrm{ml}$ de $100 \%$ de jugo de camu-camu, que correspondía a $1050 \mathrm{mg}$ de vitamina C, durante 7 días; y otro grupo que tomó $1050 \mathrm{mg}$ de comprimidos de vitamina C. Después de este tiempo se observaron los marcadores de estrés oxidativo, tales como los niveles de 8-hidroxi-urinário desoxiguanosina $(\mathrm{p}<0,05)$ y total de especie reactiva de oxígeno $(\mathrm{p}<0,01)$ y de marcadores inflamatorios, como los niveles séricos de alta sensibilidad proteína $C$ reactiva $(\mathrm{p}<005)$, interleucina (IL)-6 ( $\mathrm{p}<0,05)$, $\mathrm{y}$ IL-8 ( $\mathrm{p}<0,01)$ disminuyó significativamente en el grupo que usó jugo de camu-camu, al mismo tiempo que quienes usaron los comprimidos, tubieron el mismo comportamiento.

El objetivo del presente trabajo fue evaluar el contenido de ácido ascórbico, antocianinas y polifenoles totales, en la cáscara fresca y seca de camu-camu (Myrciaria dubia (H.B.K) McVaugh) en diferentes tiempos de maduración; evaluar la actividad antioxidante usando diferentes tipos de radicales (DPPH, $\mathrm{ABTS}^{+}$y Peroxilo) en la cáscara seca y correlacionar el contenido de ácido ascórbico y polifenoles totales con la actividad antioxidante.

\section{Materiales y métodos}

Los frutos de camu-camu (maduro, pintón y verde) fueron obtenidos del sector la Chancadora, fundo "Nueva Esperanza", Provincia de Padre Abad (Aguaytía), Región Ucayali, Perú. Luego fueron separados de su pulpa, cáscara y semilla, en forma manual con la ayuda de un tamiz. En la pulpa se realizaron medidas de $\mathrm{pH}$, ${ }^{\circ}$ Brix, y acidez por titulación potenciométrica (AOAC, 1995), lográndose establecer el índice de madurez ( ${ }^{\circ}$ Brix/\%Acidez). El tratamiento de la cáscara fue inicialmente secado al vació, (60 Kp.cm ${ }^{-2}$ y $48^{\circ} \mathrm{C} \pm 2 ; 72$ horas), luego molido en molino de cuchillas, pasando por una malla de $1 \mathrm{~mm}$, seguidamente fue empacado al vacío (presión: 250 mbar) y almacenado a temperatura de congelación, para posteriormente realizar los análisis respectivos.

\subsection{Cuantificación de antocianinas}

Se realizó por el método del $\mathrm{pH}$ diferencial reportado por Rapisarda, Fanella y Maccarone (2000). Se pesó 0,5 g de muestra y se sometió a agitación por 15 minutos usando como solvente agua (SANDOVAL et al., 2002a; BURATTI et al., 2001), del filtrado, se tomaron dos alícuotas (cada alícuota de $2 \mathrm{~mL}$ ). Una alícuota se diluyó con buffer de $\mathrm{pH}$ 1,0 y la otra alícuota con buffer de $\mathrm{pH} 4,5$, la absorbancia fue registrada a $510 \mathrm{~nm}$, la concentración de antocianinas fue calculada mediante la siguiente Ecuación 1:

$C(m g / m l)=\left(A_{p H 1,0}-A_{p H=45}\right) \times 482,82 \times \frac{1000}{24825} D F$

Donde:484,82 esla masa molecular dela cianidína-3-glucósido, 24825 es la absortividad molar a $510 \mathrm{~nm}$, a $\mathrm{pH}=1,0 ; \mathrm{pH}=4,5$ es la corrección de la formación de productos de degradación, DF es el factor de dilución.

\subsection{Cuantificación de ácido ascórbico}

Se realizó por el método reportado por Hung y Yen (2002). Se hizo reaccionar $100 \mu \mathrm{L}$ de extracto acuoso, con $900 \mu \mathrm{L}$ de 2,6 diclorofenolindofenol, registrándose la absorbancia a $515 \mathrm{~nm}$, obteniéndose las cantidades de ácido ascórbico con la siguiente Ecuación 2:

$\mathrm{A}_{515 \mathrm{~nm}}=\mathrm{A}_{\text {control }}-\mathrm{A}_{\text {muestra }}$

Donde la Absorbancia control fue obtenida por la reacción de $100 \mu \mathrm{L}$ de ácido oxálico al $0,4 \%$, con $900 \mu \mathrm{L}$ de 2,6 diclorofenolindofenol.

\subsection{Cuantificación de polifenoles totales}

Esta prueba se basa en la reducción de los iones $\mathrm{Fe}^{3+}$ a $\mathrm{Fe}^{2+}$, por los polifenoles mostrando una coloración azul, formando el complejo ferrocianuro-ferroso, registrándose una máxima absorbancia a $720 \mathrm{~nm}$ teniendo como ventaja: a) La rapidez y simplicidad de la prueba debido a la formación del color azul, lo que ofrece sensibilidad y versatilidad para la determinación espectrofotométrica, b) Los resultados son directamente medidos del contenido de polifenoles solubles (PRICE; BUTLER, 1977), obteniéndose en el extracto acuoso de la cáscara seca pintón de camu-camu, mayor contenido de polifenoles. Se realizó mediante el método de Azul de Prussian, reportado por Price y Butler (1977). Se tomó 1 $\mathrm{mL}$ del extracto acuoso y se adicionó $3 \mathrm{~mL}$ de $\mathrm{FeCl}_{3} 0,1 \mathrm{M}$ en $\mathrm{HCl} 0,1 \mathrm{~N}$, y $3 \mathrm{~mL}$ de $0,008 \mathrm{M} \mathrm{K}_{3} \mathrm{Fe}(\mathrm{CN})_{6}$ la absorbancia fue registrada a $720 \mathrm{~nm}$. Los resultados se expresaron en mg Ac. Gálico.g-1 cáscara seca.

\subsection{Evaluación de la actividad antioxidante en la cáscara seca de camu-camu en tres estados de madurez}

\section{Radical 2,2-diphenyl-1-picrilhydrayl (DPPH)}

Se evaluó mediante el método descrito por Brand-Williams, Cuvelier y Berset (1995), de inhibición del radical DPPH, modificado por Sandoval et al. (2002a). Se hizo reaccionar $50 \mu \mathrm{L}$ de muestra con $950 \mu \mathrm{L}$ de DPPH $(100 \mu \mathrm{M})$ en etanol al $96 \%$, la absorbancia fue monitoreada a $515 \mathrm{~nm}$, a intervalos de 30 segundos durante 10 minutos. Para la determinación de la actividad antioxidante, los resultados fueron expresados en términos de $\mathrm{IC}_{50}, \mathrm{~K}_{2} \mathrm{y}$ Poder Antirradical (BRAND-WILLIAMS; CUVELIER; BERSET, 1995). 


\section{a) Coeficiente de inhibición $\left(I C_{50}\right)$}

Se determinó mediante un análisis de regresión del porcentaje de remanente versus la concentración necesaria de los extractos, para inhibir el 50\% del radical DPPH (BRANDWILLIAMS; CUVELIER; BERSET, 1995).

El porcentaje de remanente del radical DPPH fue calculado de la siguiente manera:(Ecuacíon 3)

$$
\% D P P H_{R E M} \frac{(D P P H) f}{(D P P H) i} \times 100
$$

Donde (DPPH) es la absorbancia del radical DPPH al final de la reacción, $(\mathrm{DPPH})$, es la absorbancia del radical al inicio de la reacción. El valor de $\mathrm{IC}_{50}$, fue expresado en términos de Ácido Ascórbico Equivalente (AAE) (KIM et al., 2002).

\section{b) Constante de velocidad $K_{2}$}

El valor de $\mathrm{K}_{2}$ es un parámetro que diferencia a los compuestos de acuerdo a la reactividad intrínseca.

Los valores de cinética de absorbancia obtenidos por la decoloración del DPPH para cada concentración de las soluciones de trabajo de la cáscara de camu-camu en tres estados de madurez, en estudio, fueron analizados mediante el programa STATISTICA/W ver 5,0 (STATSOFT, 1993). Para el cálculo del parámetro "b" se usó el modelo matemático propuesto por Da Porto et al. (2000).(Ecuacíon 4)

$\mathrm{A}=(\mathrm{t}+1)^{\mathrm{b}} \mathrm{a}$

Donde: A, es la absorbancia en cualquier tiempo t; a y b, son constantes; t, es el tiempo de reacción.

\section{c) Poder antirradical}

El poder antirradical, referido a la eficiencia de un antioxidante, fue evaluado de acuerdo a la metodología descrita por Brand-Williams, Cuvelier y Berset (1995).

Para tener una mejor claridad sobre la capacidad que tiene un antioxidante para inhibir radicales libres, esta parte del trabajo se realizó utilizando el Software de Sistema de Modelamiento Molecular - HyperChem (Vérsion 6,01) (STATSOFT, 2000), determinando el Análisis Conformacional de Mínima Energía, reportado por Van Acker et al. (1996); Vajragupta, Boonchoong, Wongkrajang (2000) y Webb et al. (2000).

\section{Catión 2,2, - azinobis}

\section{(3 - etilenbenzotiazolino-6 ácido sulfónico) $\left(\right.$ ABTS $\left.^{+}\right)$}

Se realizó de acuerdo al método reportado por Pelligrini et al., (1999), $100 \mu \mathrm{L}$ de las diluciones de los extractos acuosos de cáscara de camu-camu seco en tres estados de madurez y a diferentes concentraciones, se hizo reaccionar con $900 \mu \mathrm{L}$ de $\mathrm{ABTS}^{+}$por un tiempo de 10 minutos, registrándose la absorbancia a $734 \mathrm{~nm}$ a intervalos de 30 segundos.

La actividad antioxidante fue expresada como $\mathrm{IC}_{50}$, $\mathrm{y}$ en términos de Ácido Ascórbico Equivalente (AAE) (KIM et al., 2002).

\section{Radical peroxilo}

Se empleó el método de TRAP (Poder Total de Actividad Reductora) modificado por Sandoval et al. (2002a). $10 \mu \mathrm{L}$ de los extractos acuosos a diferentes concentraciones de la cáscara seca de camu-camu en diferentes estados de madurez, se hizo reaccionar con $990 \mu \mathrm{L}$ de la solución stock de radical peroxilo. La disminución de la absorbancia fue registrada a $414 \mathrm{~nm}$ a intervalos de 30 segundos durante 10 minutos. La actividad antioxidante fue expresada como $\mathrm{IC}_{50}$, y en términos de Ácido Ascórbico Equivalente (AAE) (KIM et al., 2002).

\subsection{Análisis estadístico}

Los datos de absorbancia registrados para los modelos in vitro del radical $\mathrm{DPPH}^{\circ}$, Catión $\mathrm{ABTS}^{+}$, y radical Peroxilo fueron evaluados mediante un Arnol para determinar el IC (BRAND-WILLIAMS; CUVELIER; BERSET, 1995). Los datos de absorbancia registrados para los modelos in vitro del radical DPPH, catión $\mathrm{ABTS}^{+}$y radical Peroxilo, fueron sometidos a un análisis de regresión lineal para determinar el $\mathrm{K}_{2}$, asimismo los datos de absorbancia de polifenoles totales y ácido ascórbico, para ser expresados en términos de Ac. Gálico Equivalentes (AGE) y Ácido Ascórbico Equivalente (AAE), respectivamente (ESPÍN et al., 2000; KIM et al., 2002; CALZADA, 1976).

Los valores calculados en las pruebas de actividad antioxidante, polifenoles totales, ácido ascórbico y antocianinas fueron expresados como promedio \pm desviación estándar (CALZADA, 1976; RODRÍGUEZ, 1991). Los valores de IC $_{50}$ y cantidad de ácido ascórbico, antocianinas y polifenoles totales, se evaluaron estadísticamente mediante un Diseño Completamente al Azar (DCA), con tres repeticiones, usando la prueba de t-student, $\mathrm{p}<0,05$ (CALZADA, 1976; RODRÍGUEZ, 1991).

\section{Resultados y discusiones}

\section{1 Índice de madurez}

Los resultados expresados en media $\pm S D, n=3, p<0,05$, del índice de madurez, ( ${ }^{\circ}$ Brix $/ \%$ Acidez), realizados al fruto de camu-camu, en tres estados de madurez fue de 2,41 $\pm 0,03$; $1,90 \pm 0,01$ y $1,31 \pm 0.01(\mathrm{p}<0,05)$, para la fruta madura, pintón y verde respectivamente, que nos indica, el estadio de desarrollo de la fruta, que está generalmente asociado con la comestibilidad óptima (WILLS et al., 1984). Zapata y Dufour (1993), obtuvieron 2,2; 1,8 y 1,6 para la fruta madura, pintón y verde, respectivamente. Observándose que los resultados obtenidos coinciden con los resultados obtenidos por Zapata y Dufour (1993).

\subsection{Cuantificación de antocianinas}

En el Tabla 1, se muestra el contenido de antocianinas, observándose que en estado fresco la cáscara madura de camucamu, presenta mayor contenido.

El proceso de extracción es afectado por factores como: temperatura, velocidad de agitación, polaridad del solvente y 
tamaño de la partícula, los que permiten lograr un buen contacto del sólido con el solvente, incrementando el proceso de difusión, mejorando la transferencia de los diversos componentes sólidos y disminuyendo el tiempo de extracción (GEANKOPLIS, 1982; SINGH; HELDMAN, 1998).

Luego del secado, las antocianinas no son detectadas, debido a que sufrieron degradación, básicamente al reaccionar con el ácido ascórbico (OZKAN et al., 2002), así como también con el peróxido de hidrógeno, que se forma a partir de la reacción del ácido ascórbico con el agua y las enzimas presentes en la cáscara de la fruta (OZKAN et al., 2002; SING DE UGAZ, 1997; FERNÁNDEZ, 1995).

Ozkan et al. (2002), investigó la degradación cinética de antocianinas de frutas como la granada, fresa y cereza, usando peróxido de hidrógeno a diferentes concentraciones y temperaturas, encontrando que en solución acuosa, el peróxido de hidrógeno puede fácilmente descomponerse en productos muy reactivos como el anión Perhidroxil $\left(\mathrm{HO}_{2} \cdot\right)$ y el Hidroxil $\left(\mathrm{OH}^{*}\right)$, llegando a la conclusión que el radical ${ }^{\star} \mathrm{OH}$ es la especie más reactiva que ataca al anillo bencénico de los compuestos fenólicos, degradando al sustrato en $\mathrm{CO}_{2} \mathrm{y} \mathrm{H}_{2} \mathrm{O}$, asimismo da a conocer que las quinonas formadas por la oxidación de fenoles, pueden favorecer el deterioro de las antocianinas, estableciendo que la degradación cinética, fue del modelo de primer orden, logrando calcular el tiempo necesario de degradación del $50 \%$ de antocianinas, determinando que las antocianinas de la cereza presentan mayor resistencia, atribuyéndosele a la presencia de cianidinas, además estas frutas, poseen cantidades insignificantes de ácido ascórbico.

\subsection{Cuantificación de ácido ascórbico}

Como se puede observar en la Figura 1, el mayor contenido de ácido ascórbico en estado fresco se presenta en la cáscara de camu-camu madura con 21,95 $\pm 1,18$ mg Ac. Ascórbico.g ${ }^{-1}$ muestra, seguida por el pintón 20,50 $\pm 0,39 \mathrm{mg}$ Ac. Ascórbico.g ${ }^{-1}$ muestra y luego la verde 13,78 $\pm 1,24 \mathrm{mg}$ Ac. Ascórbico.g ${ }^{-1}$ muestra, datos expresados en media $\pm S D, n=3, p<0,05$.

Luego del secado, el mayor contenido de ácido ascórbico se presenta en la cáscara del fruto pintón con 53,49 \pm 9,40 mg Ac. Ascórbico.g $\mathrm{g}^{-1}$ muestra, seguido por la cáscara del fruto maduro 16,41 $\pm 3,64$ mg Ac. Ascórbico.g ${ }^{-1}$ muestra y luego la cáscara del fruto verde 15,38 \pm 5,81 mg Ac. Ascórbico.g-1 muestra $(\mathrm{p}<0,05)$, esta variación de concentración de ácido ascórbico, presenta relación con el contenido de acidez, debido a que los ácidos presentes en la fruta, facilitan la degradación del ácido ascórbico,

Tabla 1. Contenido de antocianinas en la cáscara de camu-camu.

\begin{tabular}{lcc}
\hline Cáscara & & Cianidina-3-glucósido $\left(\mathrm{mg} . \mathrm{L}^{-1}\right)^{1}$ \\
\hline Fresco & Maduro & $46,42 \pm 0,52^{\mathrm{a}}$ \\
& Pintón & $3,83 \pm 0,11^{\mathrm{b}}$ \\
\multirow{2}{*}{ Seco } & Maduro & $\mathrm{ND}$ \\
& Pintón & $\mathrm{ND}$ \\
\hline
\end{tabular}

${ }^{1}$ Datos expresados en media \pm SD, $n=3, p<0,05$. ND: No detectado. Medias seguidas de las letras diferentes se diferencian entre si. así como la presencia de enzimas, antocianinas, paralelamente el ácido ascórbico es deteriorado por la presencia de agua, que es proporcionado por la fruta (LEE; CHEN, 1998; BRADSHAW; PRENZLER; SCOLLARY, 2001).

\subsection{Cuantificación de polifenoles totales}

En el Tabla 2, se muestra los resultados de la cuantificación de polifenoles totales $(\mathrm{p}<0,05)$.

Kahkomen et al. (1999), cuantificaron el contenido de polifenoles usando el método de Folin-Ciocalteu, en muestras de cáscara de papa (Solanum tuberosum Rosamunda, 4,3 mg AGE/peso seco), papa (Solanum tuberosum Matilda, $2,5 \mathrm{mg}$ AGE/peso seco), remolacha (Beta vulgaris esculenta, 4,3 mg AGE/peso seco), tomate (lycopersicum esculentum, 2,0 mg AGE/peso seco), en hierbas medicinales de lupinus azul (Lupinus angustifolius, 4,7 mg AGE/peso seco), romero de pantano (Andrómeda polifoliaglaucophylla, 32,8 mg AGE/peso seco), tomillo (Tymus vulgaris, 17,1 mg AGE/peso seco), y en el trebol rojo (red clover, 7,8 mg AGE/peso seco).

De acuerdo a éstos resultados, la cáscara de camu-camu, presenta mayor contenido de polifenoles que la cáscara de papa, remolacha, tomate, lupinus azul y trébol rojo, siendo superado sólo por las muestras de tomillo y romero.

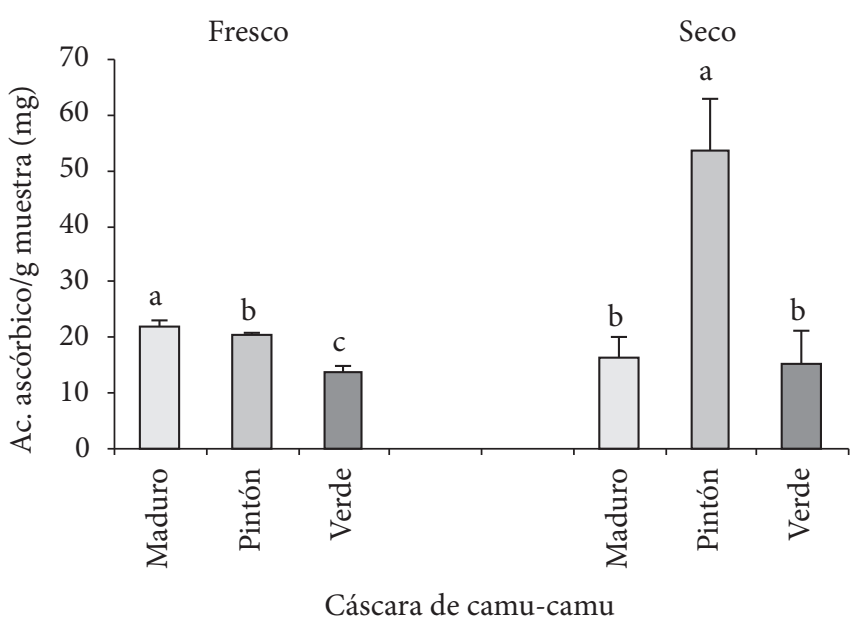

Figura 1. Contenido de ácido ascórbico en la cáscara de camu-camu en estado fresco y seco.

Tabla 2. Contenido de polifenoles totales en la cáscara seca de camucamu.

\begin{tabular}{cc}
\hline Cáscara & mg Ac. Gálico.g ${ }^{-1}$ \\
\hline Maduro & $6,02 \pm 0,48^{\mathrm{a}}$ \\
Pintón & $7,70 \pm 0,26^{\mathrm{b}}$ \\
Verde & $5,95 \pm 0,13^{\mathrm{a}}$ \\
\hline
\end{tabular}

${ }^{1}$ Datos expresados en media \pm SD, $n=3, p<0,05$. Medias seguidas de las letras diferentes se diferencian entre si 


\subsection{Evaluación de la actividad antioxidante}

\section{Radical 2,2 diphenyl-1-picrilhydrazyl (DPPH)}

En las Figuras 2, 3 y 4, se muestran las cinéticas de reacción del radical DPPH frente a los extractos acuosos de la cáscara seca de camu-camu en tres estados de madurez.

El radical DPPH, es útil para evaluar la actividad antirradical de polifenoles (LEBEAU et al., 2000), así como la toxicidad en células y extractos microbianos (KO et al., 1998; LARRAURI; SANCHEZ-MORENO; SAURA-CALIXTO, 1998; HU; KITTS, 2000).

Los resultados de la actividad antioxidante de la cáscara de camu-camu, muestran que el extracto acuoso de la cáscara pintón tuvo mayor eficiencia para inhibir el radical DPPH con $92,89 \pm 0,44 \%$; seguido con $90,17 \pm 3,02 \%$ y $82,62 \pm 8,54 \%$; para la cáscara del fruto maduro y verde respectivamente, datos expresados en media $\pm S D, n=3, p<0,05$ (Figura 5).

Los resultados, obtenidos por Yen y Chen (1995), que evaluaron la actividad antioxidante con diferentes muestras de té, encontraron que el té pouchong, presentó mayor inhibición, seguido por el té verde, el té oolong y té negro con 66,1 , $59,4,54,6$ y 49\%, respectivamente. Asimismo, la actividad antioxidante de extractos de yacón realizado con diferentes solventes como el cloroformo, acetato de etilo, y acetona, inhibieron un 13,8; 17 y 20,5\% respectivamente (YAN et al., 1999), del cual destacamos que los extractos acuosos de las muestras de cáscara de camu-camu presentan mayor actividad para inhibir el radical DPPH.

\section{a) Coeficiente de inhibición $\left(I_{50}\right)$}

De acuerdo con éste parámetro, bajos valores de $\mathrm{IC}_{50}$ reflejan una alta actividad para inhibir radicales libres (ANCOS; GONZALES; CANO, 2000), obteniéndose que el extracto acuoso de la cáscara seca de camu-camu pintón presenta el mayor porcentaje de inhibición (Tabla 3).

Observándose diferencia $(\mathrm{p}<0,05)$, entre los extractos acuosos de la cáscara de camu-camu en diferentes estados de madurez.

De las muestras en estudio, la muestra de cáscara del fruto pintón es 2,47 y 2,54 veces más fuerte que las muestras de cáscara del fruto maduro y verde.

Estos resultados tienen una correlación directa con el contenido de ácido ascórbico $r=0,999$ y polifenoles $r=0,999$, de la cual deducimos que éstos componentes actúan directamente en la reacción de inhibición frente al radical DPPH.

Lebeau et al. (2000), calcularon valores de $\mathrm{IC}_{50}$ con estándares puros de BHT $\left(12,56 \mu \mathrm{g} \cdot \mathrm{mL}^{-1}\right)$, Quercetina $\left(0,43 \mu \mathrm{g} \cdot \mathrm{mL}^{-1}\right)$, Flavonas (46,84 $\left.\mu \mathrm{g} \cdot \mathrm{mL}^{-1}\right)$. Asimismo Ramos (2001), calculó valores de $\mathrm{IC}_{50}$ para el té verde y hierba luisa, obteniendo $32,43 \mathrm{y}$ $1345,79 \mu \mathrm{g} \cdot \mathrm{mL}^{-1}$, respectivamente, observándose que la muestra de cáscara de camu-camu pintón, presenta el mejor coeficiente de inhibición, respecto a la muestra de hierba luisa, las flavonas y las cáscaras de camu-camu maduro y verde, siendo superados por el Té, BHT y Quercetina.

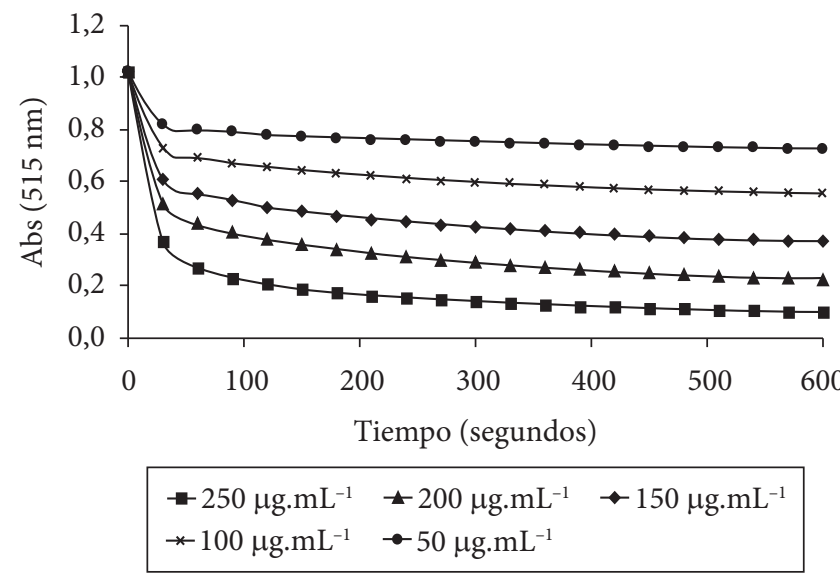

Figura 2. Cinética de reacción del radical DPPH frente al extracto acuoso de la cáscara seca de camu-camu maduro.

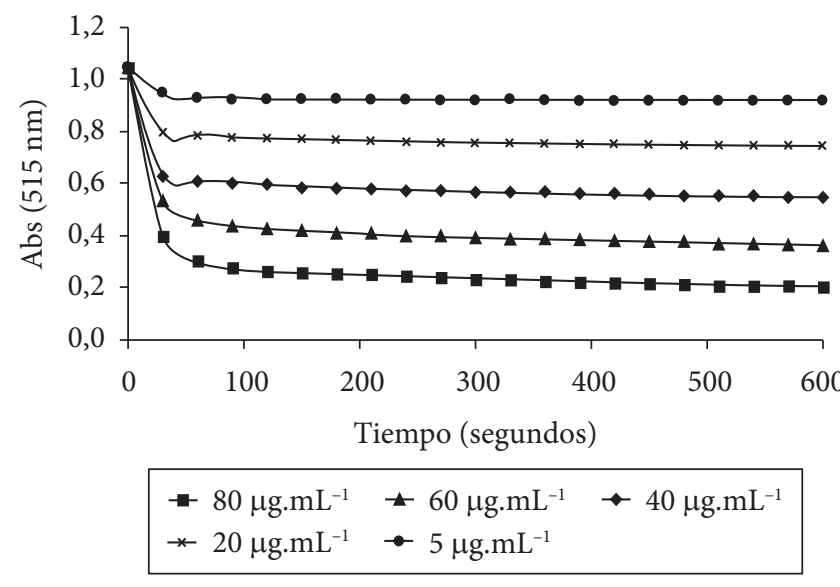

Figura 3. Cinética de reacción del radical DPPH frente al extracto acuoso de la cáscara seca de camu-camu pintón.

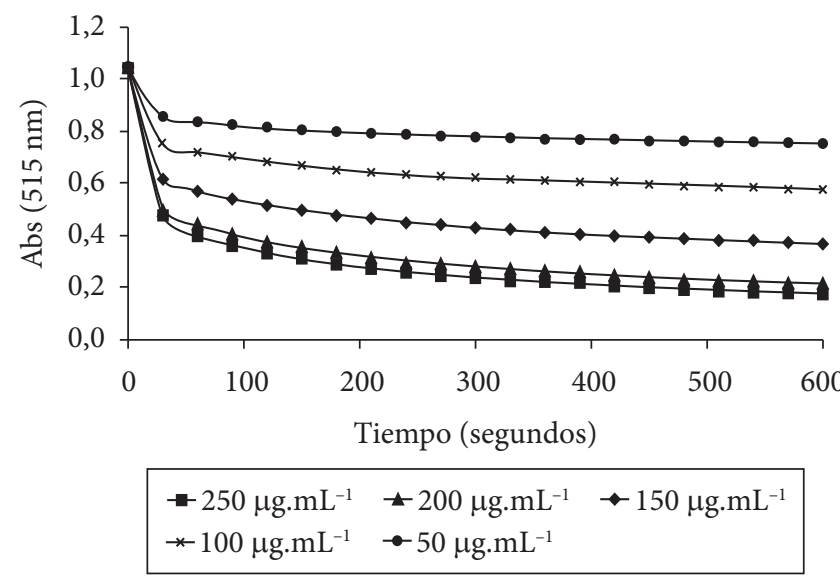

Figura 4. Cinética de reacción del radical DPPH frente a los extractos acuosos de la cáscara seca de camu-camu verde. 
b) Constante de velocidad $\left(K_{2}\right)$

El valor del $\mathrm{K}_{2}$ para los extractos acuosos de cáscara de camu-camu madura, pintón y verde fueron de $1,32\left(\mathrm{mg} \cdot \mathrm{mL}^{-1}\right)^{-1}$ $\operatorname{Ln}(\mathrm{s})^{-1} \pm 0,11 ; 4,04\left(\mathrm{mg} \cdot \mathrm{mL}^{-1}\right)^{-1} \operatorname{Ln}(\mathrm{s})^{-1} \pm 0,18$ y $1,27\left(\mathrm{mg} \cdot \mathrm{mL}^{-1}\right)^{-1}$ $\operatorname{Ln}(s)^{-1} \pm 0,02$, respectivamente.

Lebeau et al. (2000), y Espín et al. (2000), realizaron cálculos de actividad antioxidante con estándares puros de flavonas $\left(1,2 \mathrm{~L} \cdot \mathrm{mol}^{-1} / \mathrm{s}\right)$, Vitamina E $\left(1,87\left(\mathrm{mg} \cdot \mathrm{mL}^{-1}\right)^{-1} / \mathrm{s}\right)$, BHT $\left(0,05\left(\mathrm{mg} \cdot \mathrm{mL}^{-1}\right)^{-1} / \mathrm{s}\right)$, BHA $\left(0,42\left(\mathrm{mg} \cdot \mathrm{mL}^{-1}\right)^{-1} / \mathrm{s}\right)$, lo que significa, que las muestras en estudio poseen una buena actividad de secuestro de radicales.

Tabla 3. Coeficiente de Inhibición $\mathrm{IC}_{50}$, de la cáscara de camu-camu seca frente al radical DPPH.

\begin{tabular}{crc}
\hline Cáscara & $\mathrm{IC}_{50}\left(\mu \mathrm{g} \cdot \mathrm{mL}^{-1}\right)^{1}$ & $\mathrm{AAE}^{*}(\mu \mathrm{M})$ \\
\hline Maduro & $114,20 \pm 0,98^{\mathrm{a}}$ & $20,61 \pm 0,30^{\mathrm{a}}$ \\
Pintón & $46,20 \pm 0,10^{\mathrm{b}}$ & $21,24 \pm 0,16^{\mathrm{ab}}$ \\
Verde & $117,80 \pm 0,65^{\mathrm{a}}$ & $20,48 \pm 0,49^{\mathrm{b}}$ \\
\hline
\end{tabular}

${ }^{1}$ Datos expresados en media \pm SD, $n=3, p<0,05$. Evaluado luego de 10 minutos de reacción. AAE*: Ácido Ascórbico Equivalente. $\mu \mathrm{M}$ : Micromolar. Medias seguidas de las letras diferentes se diferencian entre si.

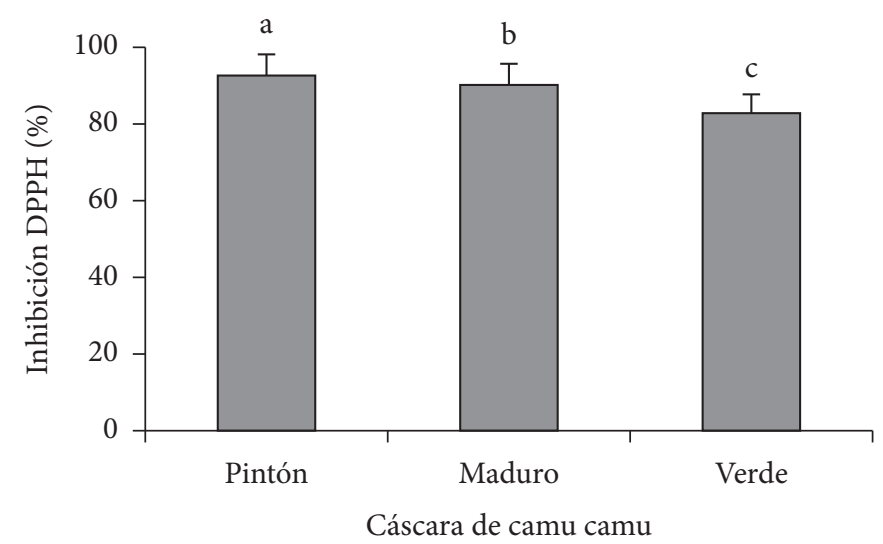

Figura 5. Porcentaje de inhibición del radical DPPH, frente a los extractos acuosos de la cáscara de seca camu-camu, evaluado luego de 10 minutos de reacción.
El valor de $\mathrm{K}_{2}$ obtenido por Ramos (2001), en la que evaluó la actividad antioxidante del té verde y hierba luisa, fue de 2,3 (mg.mL $\left.{ }^{-1}\right)^{-1} \operatorname{Ln}(\mathrm{s})^{-1}$ y $0,06\left(\mathrm{mg} \cdot \mathrm{mL}^{-1}\right)^{-1} \mathrm{Ln}(\mathrm{s})^{-1}$. De acuerdo a nuestros resultados, el siguiente orden en función a la mayor velocidad de reacción es: cáscara de camu-camu pintón> té $>$ vitamina $\mathrm{E}>$ cáscara de camu-camu maduro $>$ cáscara de camu-camu verde $>$ flavonas $>$ BHA $>$ BHT. Estableciéndose que la cáscara de camu-camu pintón, presenta la mayor velocidad de reacción $\left(\mathrm{K}_{2}=4,04\left(\mathrm{mg} \cdot \mathrm{mL}^{-1}\right)^{-1} \mathrm{Ln}(\mathrm{s})^{-1}\right)$, debido al mayor contenido de ácido ascórbico.

\section{c) Poder antirradical (ARP)}

El valor de ARP, en parte explica la capacidad que tiene el antioxidante, para neutralizar un radical libre (donación de hidrógenos), teniendo una relación directa con la acción inhibidora (BRAND-WILLIAMS; CUVELIER; BERSET, 1995). El valor del ARP para los extractos acuosos de cáscara de camucamu madura, pintón y verde fueron de $0,88 \pm 1,01 ; 2,17 \pm 0,18$ y 0,85 $\pm 3,94$. Brand-Williams, Cuvelier y Berset (1995), calcularon el ARP con estándares puros de ácido rosmarínico, BHA, BHT, $\alpha$-tocoferol obteniendo valores de 6,$9 ; 4,17 ; 4,2$ y 4,0 respectivamente.

En la primera etapa, el ácido ascórbico, cede un hidrógeno, debido a la diferencia en la banda de energía entre el radical DPPH y el ácido ascórbico $(5,19 \mathrm{eV})$ (Figura 6). Produciéndose una transferencia de electrones de doble enlace, hacia el oxígeno, que sufrió la pérdida de un electrón, repitiendo la misma acción en el siguiente átomo de oxígeno, que sufrió la pérdida del átomo de hidrógeno, hasta establecerse el equilibrio de energía. De acuerdo a esta reacción, el ácido ascórbico cede dos hidrógenos, explicando así su eficiencia como un excelente antioxidante.

\section{Catión 2,2-azinobis (3-etilbenzotiazoline - 6 ácido sulfónico) $\left(\right.$ ABTS $\left.^{+}\right)$}

Este radical, es utilizado ampliamente para medir la actividad antioxidante en el plasma sanguíneo, y fluidos biológicos (RE et al., 1999; PSOTOVÁ et al., 2001), así como para los carotenoides y compuestos fenólicos (PELLEGRINI et al., 1999), adicionalmente se puede medir el potencial antioxidante de muestras de drogas (CALBIOCHEM, 2000).

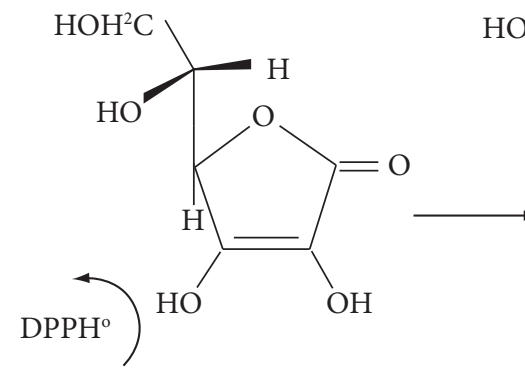

Ácido ascórbico

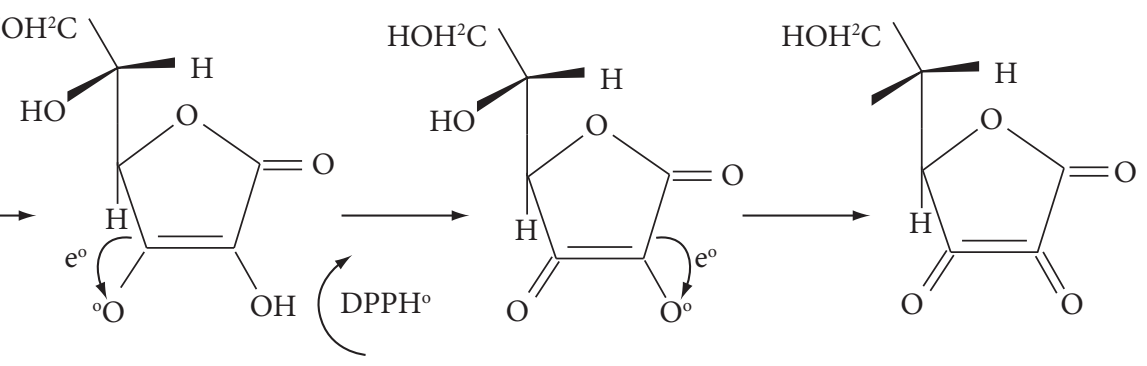

Ácido deshidroascórbico

Figura 6. Mecanismo de reacción del ácido ascórbico frente al radical DPPH evaluado mediante simulación computacional con el software Hyperchem 6,01. 
La actividad antioxidante fue evaluada a $734 \mathrm{~nm}$, con cinco diferentes concentraciones, comprendiendo un rango óptimo de inhibición. El porcentaje de inhibición fue calculado luego de diez minutos de reacción, para cada extracto (Figura 7).

De los resultados mostrados en la Figura 7, se aprecia un incremento proporcional entre el porcentaje de inhibición del $\mathrm{ABTS}^{+}$y la concentración de los extractos obtenidos de la cáscara de camu-camu en los diversos estados de madurez, obteniéndose un porcentaje de inhibición de 99,35 $\pm 0,46$; $75,23 \pm 13,81$ y $67,39 \pm 2,99 \%$; ( $p<0,05)$, para las muestras de cáscara de fruto pintón, verde y maduro respectivamente.

En la reacción de reducción del $\mathrm{ABTS}^{+}$frente a los extractos acuosos en estudio, monitoreado a $734 \mathrm{~nm}$, se observa que el mayor porcentaje de inhibición está comprendido entre 0-2 minutos (Figura 8). La reacción de la actividad antioxidante del ácido ascórbico y otros compuestos fenólicos frente al $\mathrm{ABTS}^{+}$ presenta una cinética de reacción bifásica (KIM et al., 2002).

\section{a) Coeficiente de inhibición $\left(I C_{50}\right)$}

El cálculo del correspondiente valor de $\mathrm{IC}_{50}$, fue realizado mediante el ploteo de los porcentajes de inhibición, respecto a sus respectivas concentraciones. En el Tabla 4, se muestra el
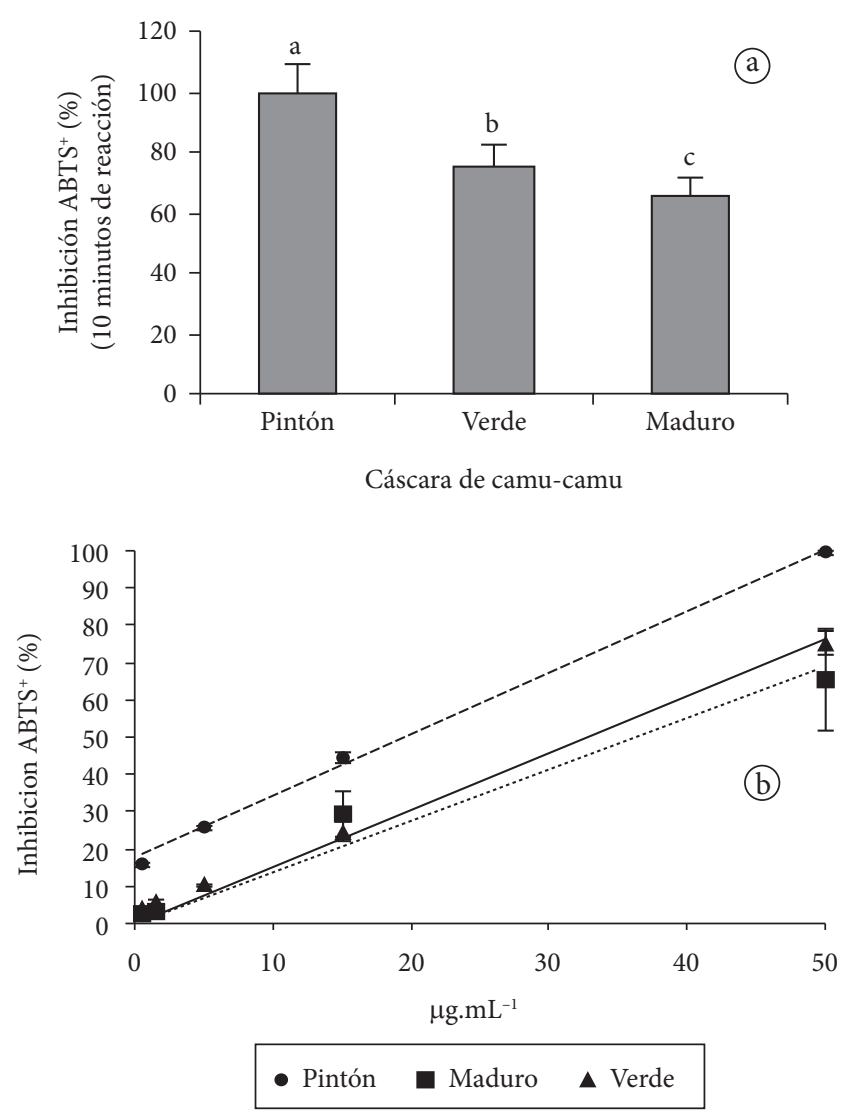

Figura 7. Porcentaje de inhibición de los extractos acuosos de la cáscara seca de camu-camu, frente al catión $\mathrm{ABTS}^{+}$. coeficiente de inhibición $\mathrm{IC}_{50}$, de la cáscara seca de camu-camu frente al catión $\mathrm{ABTS}^{+}$.

El valor de $\mathrm{IC}_{50}$ para la cáscara del fruto maduro, pintón y verde fue de 33,$76 ; 20,25$ y $32,54 \mu \mathrm{g} . \mathrm{mL}^{-1}$ respectivamente, estos valores de $\mathrm{IC}_{50}$, comparados con los obtenidos por Sandoval et al. (2002b), en la que evaluaron la actividad antioxidante con muestras de uña de gato (Uncaria tomentosa y uncaria guianensis), y en los que obtuvieron valores de 7,7 y $4,8 \mu \mathrm{g} \cdot \mathrm{mL}^{-1}$, evidencian ser más eficientes que las muestras de camu-camu, debido a que los extractos de uña de gato, antes de los experimentos fueron liofilizados, así mismo este recurso presenta buenas propiedades antiinflamatorias.

El coeficiente de correlación frente al ácido ascórbico y polifenoles totales fue de $r=0,994 \mathrm{yr}=0,993$, destacando una correlación positiva, para el extracto acuoso de la cáscara de camu-camu pintón, reflejado en el contenido de ácido ascórbico y polifenoles totales (Figura 2, Tabla 2), éstos resultados demuestran que en la cáscara del fruto maduro y verde, el ácido ascórbico y los polifenoles no son los únicos responsables de la actividad antioxidante, suponiendo la acción de terceros componentes (PRIOR et al., 1998; KAHKOMEN et al., 1999; ZHENG; WANG, 2001).

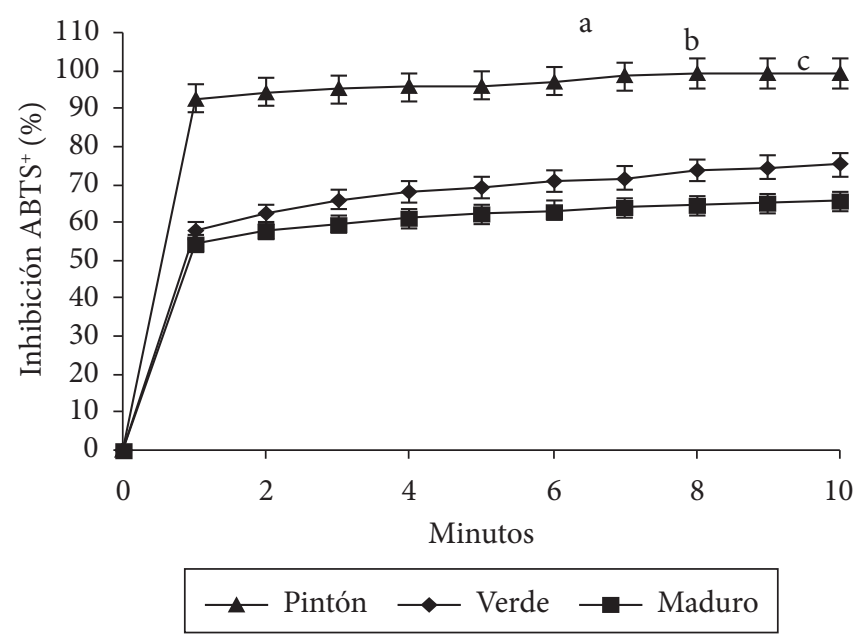

Figura 8. Reacción de inhibición del catión $\mathrm{ABTS}^{+}$, frente a los extractos acuosos de la cáscara seca de camu-camu $\left(50 \mu \mathrm{g} \cdot \mathrm{mL}^{-1}\right)$, evaluado luego de diez minutos de reacción.

Tabla 4. Coeficiente de inhibición $\mathrm{IC}_{50}$, de la cáscara seco de camu-camu frente al catión $\mathrm{ABTS}^{+}$.

\begin{tabular}{ccc}
\hline Cáscara & $\mathrm{IC}_{50}\left(\mu \mathrm{g} \cdot \mathrm{mL}^{-1}\right)^{1}$ & $\mathrm{AAE}^{\star}(\mu \mathrm{M})$ \\
\hline Maduro & $33,76 \pm 5,47^{\mathrm{b}}$ & $11,63 \pm 0,45^{\mathrm{b}}$ \\
Pintón & $20,25 \pm 0,19^{\mathrm{a}}$ & $13,22 \pm 0,26^{\mathrm{a}}$ \\
Verde & $32,54 \pm 1,34^{\mathrm{b}}$ & $12,07 \pm 0,18^{\mathrm{b}}$ \\
\hline
\end{tabular}

${ }^{1}$ Datos expresados en media \pm SD, $n=3, p<0,05$. Evaluado luego de 10 minutos de reacción. $\mathrm{AAE}^{\star}$ : Ácido Ascórbico Equivalente. $\mu \mathrm{M}$ : Micromolar. Medias seguidas de las letras diferentes se diferencian entre si. 


\section{Radical peroxilo}

En la Figura 9, se muestra las reacciones del radical peroxilo, frente al extracto acuoso de la cáscara seca de camu-camu.

En el presente experimento, la reacción de inhibición del radical peroxilo, por las muestras de cáscara de camucamu (5-25 $\left.\mu \mathrm{g} \cdot \mathrm{mL}^{-1}\right)$, presentó una buena eficiencia, que fue determinado por la adición de los extractos acuosos $(100 \mu \mathrm{L})$, con $900 \mu \mathrm{L}$ de radical peroxilo. La disminución de la absorbancia fue medida continuamente cada 30 segundos por un tiempo de 10 minutos. Obteniéndose el siguiente orden en cuanto a porcentaje de inhibición: Extracto acuoso de cáscara de fruto pintón $>$ extracto acuoso cáscara de fruto verde $>$ extracto acuoso cáscara de fruto maduro ( $\mathrm{p}<0,05)$, con 96,70 $\pm 1,07$, $82,39 \pm 0,30$ y $77,45 \pm 1,71 \%$ respectivamente.

\section{a) Coeficiente de inhibición $\left(I C_{50}\right)$}

La formación del radical peroxilo es un paso importante en la peroxidación de lípidos (SANDOVAL et al., 2002a). Los valores de $\mathrm{IC}_{50}$ de los extractos acuosos para el radical peroxilo fueron de 8,$30 ; 12,21$ y $14,39 \mu \mathrm{g} \cdot \mathrm{mL}^{-1}(\mathrm{p}<0,05)$, para las muestras de cáscara de frutos pintón, verde y maduro respectivamente (Tabla 5).

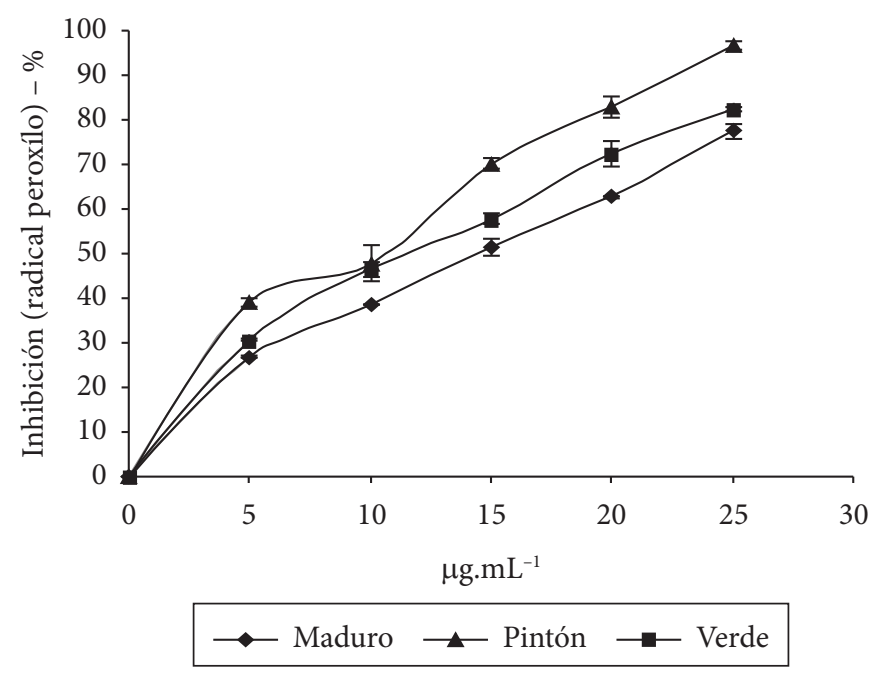

Figura 9. Inhibición del radical peroxilo frente a los extractos acuosos de la cáscara seca de camu-camu, evaluado luego de diez minutos de reacción.

Tabla 5. Coeficiente de Inhibición $\mathrm{IC}_{50}$, de la cáscara seca de camucamu frente al radical peroxilo

\begin{tabular}{ccl}
\hline Cáscara & $\mathrm{IC}_{50}\left(\mu \mathrm{g} \cdot \mathrm{mL}^{-1}\right)^{1}$ & $\mathrm{AAE}^{*}(\mu \mathrm{M})$ \\
\hline Maduro & $14,39 \pm 0,08^{\mathrm{a}}$ & $10,53 \pm 0,42^{\mathrm{a}}$ \\
Pintón & $8,30 \pm 0,85^{\mathrm{b}}$ & $11,09 \pm 0,21^{\mathrm{a}}$ \\
Verde & $12,21 \pm 0,35^{\mathrm{c}}$ & $10,74 \pm 0,14^{\mathrm{a}}$ \\
\hline
\end{tabular}

${ }^{1}$ Datos expresados en media $\pm S D, n=3, p<0,05$. Evaluado luego de 10 minutos de reacción. $\mathrm{AAE}^{\star}$ : Ácido Ascórbico Equivalente, $\mu \mathrm{M}$ : Micromolar. Medias seguidas de las letras diferentes se diferencian entre si.
Sandoval et al. (2002a), evaluaron la actividad antioxidante de la maca (Lepidium meyenii), frente al radical peroxilo obteniendo un valor de $\mathrm{IC}_{50}$ de $430 \mu \mathrm{g} \cdot \mathrm{mL}^{-1}$ destacándose una mayor eficiencia de las muestras de cáscara de camu-camu, indicando que las muestras en experimento contribuyen a la disminución de la formación de radicales peroxilo (DEAN; GIESEG; DAVIES, 1993; SANDOVAL et al., 2002a), presentando una correlación lineal con el contenido de ácido ascórbico $(r=0,926)$ y polifenoles $(r=0,923)$; destacando que en las muestras de cáscara de fruto maduro y verde (Figura 1, Tabla 2), la acción de inhibición, está influenciado por otros componentes presentes en la muestra (PRIOR et al., 1998; KAHKOMEN et al., 1999; ZHENG y WANG, 2001).

\section{Conclusiones}

- La cáscara de camu-camu en estado fresco que presentó el mayor contenido en antocianinas y ácido ascórbico fue la madura con 46,42 mg Cianidina-3-glucosido/L y 21,95 mg Ac. Ascórbico/g muestra, respectivamente;

- En estado seco, no se detectó en la cáscara la presencia de antocianinas; el mayor contenido en ácido ascórbico y polifenoles totales lo presentó la cáscara del fruto pintón con 53,49 mg Ac. Ascórbico/g muestra y 7,70 mg Ácido Gálico/g muestra, respectivamente;

- La mayor actividad antioxidante lo presentó el extracto acuoso de la cáscara seca del fruto pintón, con $\mathrm{IC}_{50}=46,20 \mu \mathrm{g} \cdot \mathrm{mL}^{-1} ; 20,25 \mu \mathrm{g} \cdot \mathrm{mL}^{-1}$ y $8,30 \mu \mathrm{g} \cdot \mathrm{mL}^{-1}$ frente a los radicales DPPH; $\mathrm{ABTS}^{+}$y Peroxilo, respectivamente; y

- La correlación de la actividad antioxidante, con el contenido de ácido ascórbico y polifenoles totales de la cáscara seca pintón respecto al radical $\mathrm{DPPH}$ fue de $r=0,999$ y $r=0,999$; para el catión $\mathrm{ABTS}^{+} \mathrm{r}=$ 0,994 y $r=0,993$, y para el radical Peroxilo $r=0,926$ y $r=0,923$, respectivamente; disminuyendo el coeficiente de correlación del ácido ascórbico y polifenoles totales para el catión $\mathrm{ABTS}^{+}$y radical peroxilo, suponiendo que la inhibición estaría influenciada por la acción de otros componentes no evaluados en este experimento.

\section{Referencias}

ANCOS, B.; GONZALES, E. M.; CANO, M. P. Ellagic acid, vitamin $\mathrm{C}$ and total phenolic contents and radical scavenging capacity affected by freezing and frozen storage in raspberry fruit. Journal of Agricultural and Food Chemistry, v. 48, n. 10, p. 4565-4570, 2000.

ASSOCIATION OF OFFICIAL ANALYTICAL CHEMISTS - AOAC. Vitamins and other nutrients. In: analysis. 15 ed. Gaithersburg, 1995. Official methods of

BRADSHAW, M. P.; PRENZLER, P. D.; SCOLLARY, G. R. Ascorbic Acid-Induced Browning of (+)-Catechin In a Model Wine System. Journal of Agricultural and Food Chemistry, v. 49, n. 2, p. 934-939, 2001.

BRAND-WILLIAMS, W.; CUVELIER, M. E.; BERSET, C. Use of a free radical method to evaluate antioxidant activity. Food Science and Technology, v. 28, n. 1, p. 25 -30, 1995. 
BURATTI, S. et al. Rapid electrochemical method for the evaluation of the antioxidant power of some lipophilic food extracts. Journal of Agricultural and Food Chemistry, v. 49, n. 11, p. 5136-5141, 2001.

CALBIOCHEM. General catalog. San Diego, 2000. Disponível em: <www.calbiochem.com>. Acesso em: 02 fev. 2008.

CALZADA, B. Métodos estadísticos para la investigación. 3 ed. Lima: Editora Jurídica, 1976.

DEAN, R. T.; GIESEG, S.; DAVIES, M. J. Reactive Species and their Accumulation on Radical Damaged Proteins. Trends in Biochemical Sciences, v. 18, n. 11, p. 437-441, 1993.

DREOSTI, I. E. Antioxidant polyphenols in tea, cocoa, and wine. Nutrition, v. 16, n. 7/8, p. 692-694, 2000.

ESPÍN, J. et al. Anthocyanin based colorants: a new source of antiradical activity for foodstuff. Journal of Agricultural and Food Chemistry, v. 48, n. 5, p. 1588-1592, 2000.

FERNÁNDEZ, F. Extracción y Repurificación de Antocianinas de maíz morado (Zea Maysl). 1995. (TESIS) - Universidad Nacional Agraria la Molina - UNALM, Lima.

FRIEDMAN, M. Chemistry, biochemistry, and dietary role of potato polyphenols: a review. Journal of Agricultural and Food Chemistry, v. 45, n. 5, p. 1523-1540, 1997.

GEANKOPLIS, C. H. Procesos de transporte y operaciones unitarias. México: Continental, 1982.

HU, C.; KITTS, D. D. Studies on the Antioxidant Activity of Echinacea Root Extract. Journal of Agricultural and Food Chemistry, v. 48, n. 5, p. 1466-1472, 2000.

HUNG, C. Y.; YEN, G. C. Antioxidant Activity of Phenolic Compounds Isolated from Mesona Procumbens Hemsl. Journal of Agricultural and Food Chemistry, v. 50, n. 10, p. 2993 -2997, 2002.

INOUE, T. et al. Tropical fruit camu-camu (Myrciaria dubia) has antioxidative and anti-inflammatory properties. Journal of Cardiology, n. 52, p. 127-132, 2008.

KAHKOMEN, M. P. et al. Antioxidant Activity of Plant Extracts Containing Phenolic Compounds. Journal of Agricultural and Food Chemistry, v. 47, n. 10, p. 3954-3962, 1999.

KIM, D. O. et al. Vitamin C Equivalent Antioxidant Capacity (VCEAC) of Phenolic Phytochemicals. Journal of Agricultural and Food Chemistry, v. 50, n. 13, p. 3713-3717, 2002.

KO, F. N. et al. Scavenger and Antioxidant Properties of Prenylflavones Isolated from Artocarpus heterophyllus. Free Radical Biology \& Medicine, v. 25, n. 2, p. 160-168, 1998.

LARRAURI, J. A.; SANCHEZ-MORENO, C.; SAURA-CALIXTO, F. Effect of temperature on the free radical scavenging capacity of extract from red and white grape pomace peels. Journal of Agricultural and Food Chemistry, v. 46, n. 7, p. 2694-2697, 1998.

LEBEAU, J. et al. Antioxidant Properties of Di-tert-Butylhydroxylated Flavonoids. Free Radical Biology \& Medicine, v. 29, n. 9, p. 900-912, 2000.

LEE, H. S.; CHEN, C. S. Rates of vitamin C loss and discoloration in clear orange juice concentrate during storage at temperature of 4- $24^{\circ} \mathrm{C}$. Journal of Agricultural and Food Chemistry, v. 46, n. 11, p. 4723-4727, 1998.

OZKAN, M. et al. Degradation Kinetics of Anthocyanins from Sour Cherry, Pomegranate and Strawberry Juices by Hydrogen Peroxide. Journal of Food Science, v. 67, n. 2, p. 525-529, 2002.

PELLIGRINI, N. et al. Screening of Dietary Carotenoids and Carotenoid-Rich Fruit Extracts for Antioxidant Activities Applying
2,2'-Azinobis (3-Ethylenebenzothiazoline-6-sulfonic acid) Radical Catión Decolorization Assay. Methods in Enzymology, v. 299, p. 379-389, 1999.

PERÓN, J. M. R.; LÓPEZ, J. R. M.; LÓPEZ, Y. T. Radicales Libres en la Biomedicina y Estrés Oxidatívo. Revista Cubana de Medicina Militar, v. 30, n. 1, p. 15 -20, 2001.

PORTO, C. et al. Antiradical Properties of Commercial Cognacs Assessed by $\mathrm{DPPH}^{\circ}$ Test. Journal of Agricultural and Food Chemistry, v. 48, n. 9, p. 4241-4245, 2000.

PRICE, M. L.; BUTLER, L. G. Rapid Visual Estimation Spectrophometric Determination of Tannin Content of Sorghum Grain. Journal of Agricultural and Food Chemistry, v. 25, n. 6, p. $1268-1273$, 1977.

PRIOR, R. L. et al. Antioxidant Capacity As Influenced by Total Phenolic and Anthocyanin Content, Maturity, and Variety of Vaccinium Species. Journal of Agricultural and Food Chemistry, v. 46, n. 7, p. 2686-2693, 1998.

PSOTOVÁ, J. et al. Determination of total antioxidant capacity in plasma by cyclic voltammetry: two case reports. Biomedical Papers, v. 145 , n. 2, p. 81-83, 2001.

RAMOS, F. Diseño y Evaluación de la Capacidad Antioxidativa in Vitro de una Bebida en base a Té verde (Camellia sinensis) y hierba Luisa (Cymbogon citratus Staph). In: ENCUENTRO CIENTÍFICO INTERNACIONAL DE INVIERNO - ECI, 3, del 30 de julio al 2 de agosto 2001, Tingo, María.

RAPISARDA, P.; FANELLA, F; MACCARONE, E. Reliability of Analytical Methods for Determining Anthocyanins in Blood Orange Juices. Journal of Agricultural and Food Chemistry, v. 48, n. 6, p. 2249-2252, 2000.

RE, R. et al. Antioxidant Activity Applying an Improved ABTS Radical Catión Decolorization Assay. Free Radical Biology and Medicine, v. 26, n. 9-10, p. 1231-1237, 1999.

RODRÍGUEZ, D. Métodos de investigación pecuaria. 1 ed. México: Trillas, 1991.

SANDOVAL, M. et al. Antioxidant Activity of the Cruciferous Vegetable Maca (Lepidium meyenii). Food Chemistry, v. 79, n. 2, p. 207 - 213, 2002a.

SANDOVAL, M. et al. Anti-inflammatory and Antioxidant Activities of Cat's Claw (Uncaria tomentosa and uncaria guianensis) are Independent of their Alkaloid Content. Phytomedicine, v. 9, n. 4, p. 325-337, 2002 b.

SINGH, R.; HELDMAN, D. Introducción a la ingeniería de los alimentos. Zaragoza: Acribia, 1998.

STATSOFT. Statistica Software for Windows: release 5.0. New York, 1993.

STATSOFT. HyperChem TM Program: release 6.01 for Windows. New York, 2000.

SLOAN, E. The natural and organic foods marketplace. Journal of Food Technology, v. 56, n. 1, p. 28, 2002.

THOMAS, M. J. The role of free radicals and antioxidants. Nutrition, v. 16, n. 7-8, p. 716-718, 2000.

UGAZ, O. S. Colorantes naturales. Perú: Pontificia Universidad Católica del Perú, 1997.

VAJRAGUPTA, O.; BOONCHOONG, P.; WONGKRAJANG, Y. Comparative Quantitative Structure-Activity Study of Radical Scavengers. Biorganic and Medical Chemistry, v. 8, n. 11, p. 2617-2628, 2000. 
Van ACKER, S. A. B. E. et al. A Quantum Chemical Explanation of the Antioxidant Activity of Flavonoids. Chemical Research in Toxicology, v. 9, n. 8, p. 1305-1312, 1996.

WEBB, S. R. et al. Interaction of Cyclohexanediones with Acetyl Coenzyme-A Carboxylase and an Artificial Target-Site Antibody Mimic: a comparative molecular field analysis. Journal of Agricultural and Food Chemistry, v. 48, n. 6, p. 2506-2511, 2000.

WILLS, R. et al. Fisiología y manipulación de frutas y hortalizas post-recolección. Zaragoza: Acribia, 1984.

YAN, X. et al. Extraction and Identification of Antioxidants in the Roots of Yacón (Smallanthus sonchifolius). Journal of Agricultural and Food Chemistry, v. 47, n. 11, p. 4711-4713, 1999.
YEN, G. C.; CHEN, H. Y. Antioxidant Activity of Various Tea Extracts in Relation to Their Antimutagenicity. Journal of Agricultural and Food Chemistry, v. 43, n. 1, p. 27-32, 1995.

ZANATTA, C. F. et al. Determination of Anthocyanins from Camucamu (Myrciaria dubia) by HPLC-PDA, HPLC-MS, and NMR. Journal of Agricultural and Food Chemistry, v. 53, n. 24, p. 9531-9535, 2005.

ZAPATA, S. M.; DUFOUR, J. P. Camu-camu (Myrciaria dubia McVaugh) Chemical Composition of Fruit. Journal of the Science of Food and Agriculture, v. 61, n. 3, p. 349-351, 1993.

ZHENG, W.; WANG, S. Y. Antioxidant Activity and Phenolic Compounds in Select Herbs. Journal of Agricultural and Food Chemistry, v. 49, n. 11, p. 5165-5170, 2001. 